\title{
Educação inclusiva em revistas pedagógicas: análises de conteúdo e BIBLIOMÉTRICA ${ }^{1}$ \\ INCLUSIVE EDUCATION IN EDUCATIONAL MAGAZINES: CONTENT AND BIBLIOMETRIC ANALYSIS
}

\author{
Altemir José Gonçalves BARBOSA² \\ Renata A raújo CAM POS 3
}

\begin{abstract}
RESUM 0: as revistas pedagógicas constituem um tipo de periódico educacional que têm sido amplamente lidas por professores e candidatos à docência no Brasil. Embora atuem decisivamente na formação inicial e continuada dos docentes e, por consequência, nas práticas pedagógicas adotadas em sala deaula, essas revistas têm sido pouco estudadas. A carência de estudos é ainda maior quando se trata das concepções e práticas sobre inclusão escolar veiculadas por elas. Com o objetivo de efetuar análises de conteúdo e bibliométrica de escritos sobre inclusão escolar publicados entre 1994 e 2005 em duas revistas pedagógicas, foram recuperados e analisados 40 textos, sendo 24 da revista AMAE Educando e 16 da Presença Pedagógica. As principais características bibliométricas das publicações sobre inclusão escolar dos dois periódicos são: artigos em gênero descritivo/ reportativo; autoria individual; e apresentação de referências ou bibliografias. O conteúdo desses textos tem como tema principal a inclusão escolar de forma global, sem especificar um ou mais tipos de necessidades educacionais especiais. A dotam uma abordagem educacional da inclusão escolar não delimitando níveis e/ ou tipos de ensino. Divergências entre as duas revistas foram detectadas, mas elas parecem convergir mais do que discrepar. São analisadas as limitações dos textos no que diz respeito aos fundamentos teóricos e práticos da inclusão escolar.
\end{abstract}

PALAVRAS-CHAVE: educação especial; professores; formação; necessidades educacionais especiais.

ABSTRACT: Educational magazines are a subset of educational periodicals that have been widely read by teachers and undergraduatestudents in teacher development courses in Brazil. Although they havean important role in beginning and ongoing teacher development programs, with impact on pedagogical practices used in the classroom, such magazines have not been researched. The lack of research is of even greater concern when one focuses upon the conceptions and practices of inclusive education conveyed in this kind of material. In order to perform bibliometric and content analysis of articles written between 1994 and 2005 on inclusion in schools in two educational periodicals, 40 texts were selected and analyzed, 24 from the AMAE Educando magazine and 16 from Presença Pedagógica. The main bibliometric features of the articles on inclusion of these two magazines are: descriptive or teacher reports; personal essays; and presentation of literature and references. As to the content of these articles, the main theme is inclusion in school in general, without specification as to one or more kinds of special educational needs. They adopt an educational approach for school inclusion that does not discuss teaching levels of education services. Differences between the magazines were detected, but there were more similarities than discrepancies among them. The articles' limitations were analyzed as to theoretical and practical bases for inclusion in school.

KEYWORD S: Special Education; Teachers; Teacher Education, Special Educational Needs.

\section{INTRODUÇÃO}

"A relação dos professores com o conhecimento tem sido uma questão amplamentedebatida em diferentes fóruns einstâncias" (SM OLKA; GENTIL, 2004,

\footnotetext{
${ }^{1}$ Apoio da Pró-reitoria de Pesquisa da Universidade Federal de Juiz de Fora-MG

2 Professor do Curso de Graduação e do Programa de Pós-Graduação em Psicologia do Departamento de Psicologia da UFJF altgonc@uol.com.br

${ }^{3}$ Psicóloga pela Universidade Federal de Juiz de Fora - MG - renatacampospsi@yahoo.com.br
} 
p. 194). Ler é, sem dúvida, uma das principais vias para o conhecimento. A leitura éuma atividadefundamental durantea preparação acadêmica dos novos docentes. É, ainda, um dos principais meios de formação continuada. Ser um 'bom leitor' é um pré-requisito indispensável para ser um 'bom professor'. Todavia, estudos (ver, por exemplo, BARRETO, 2006; BARROS; GOMES, 2008) têm revelado que os educadores brasilei ros não têm o hábito deler e/ ou não desenvolvem uma relação afetiva com esse comportamento.

Alguns projetos têm sido desenvolvidos para fomentar o hábito da leitura nos docentes (ver, por exemplo, MARINHO, 2004). Há que se asseverar, contudo, que ter professores-leitores não basta; também é preciso cuidar da qualidade dos materiais lidos por eles. No contexto brasileiro, porém, pouca atenção tem sido dada às leituras que eles efetuam.

Dentre os vários tipos de leituras efetuadas por docentes e candidatos à docência, optou-se por estudar as revistas pedagógicas. Trata-se de publicações periódicas com caráter educacional, destinadas à formação deeducadores. Com base em Ramos (2009), é possível afirmar que as revistas pedagógicas são meios de comunicação de massa (MCM) "que de modo geral, sem subterfúgios, indicam seu objetivo de 'educar' o educador para que ele saiba educar seus alunos” (p. 4). São amplamente divulgadas e lidas no meio escolar, sendo que algumas delas são, inclusive, doadas para escolas públicas brasileirase/ ou vendidasem bancas dejornal.

A revista pedagógi ca éum subtipo de periódico educacional. Sefor usada a classificação de Ortega, Fávero e Garcia (1998), pode ser classificado como periódico genérico.

Como o próprio nome sugere, essas publicações abordam questões gerais de educação, em função dos objetivos que regem sua proposta editorial. O interesse por parte da sociedade pelas questões educacionais e um mercado editorial promissor estão fazendo com que empresas de comunicação de massa, organizações não-governamentais e associações profissionais criem veículos próprios (p.165).

Ainda, segundo a classificação mencionada, os periódicos educacionais podem ser subdivididos em genéricos, científicos ereferenciais. Os dois primeiros tipos mencionados podem, também, serem classificados de acordo com a abrangência do conteúdo ou dos leitores-alvo, isto é, há os periódicos científicos gerais e os especializados, existem os periódicos genéricos com divulgação ampla e os com divulgação restrita.

Há que se ressaltar, também, que diferentes denominações têm sido adotadas para fazer menção aos periódicos pedagógicos. Gentil (2006) menciona, por exemplo, as seguintes al cunhas 'revistas especial izadas', 'imprensa de ensino', 'imprensa periódica educacional', 'revistas de ensino', 'revistas profissionais', 'revista técnica', 'imprensa pedagógica', 'revistas educacionais', 'revista científicopedagógica', 'revistas da imprensa periódica educacional'. 
De acordo com Silveira (2006), a primeira revista pedagógica brasileira foi A Instrução Pública (1872-1875), editada inicialmente por J. C. de Alambary, considerado, assim, ‘o fundador da imprensa didática' no país. A tualmente, o Brasil possui aproximadamente uma dezena de periódicos destinados a docentes, sendo que parte expressiva deles está disponível na Internet.

Gentil (2006) destaca que as revistas pedagógicas têm sido estudadas por diferentes áreas do conhecimento (história, linguística, educação, comunicação etc.) e constituem uma fonte preciosa de concepções, valores, metodologias de ensino. As revistas pedagógicas são, segundo Chopin (2004, p. 565), “testemunhos da circulação de conteúdos de ensino e métodos pedagógi cos". Podem desempenhar, dessa forma, um papel determinante nas práticas educacionais adotadas e nas representações dos docentes sobreo ato educativo. A o efetuar, no entanto, uma análise do estado atual da arte da história dos livros eedições didáticas, esseautor, da mesma forma que Gentil (2006), constatou que “imprensa, revistas pedagógicas, correspondência oficial oferecem um corpus detextosainda subexplorados" (p. 565).

A pesar de existir uma lacuna no conhecimento científico sobre revistas especializadas, al guns estudos têm sido realizados no Brasil e merecem destaque. Podem ser mencionados os trabalhos de Gentil (2006) - "Revistas da área da Educação e professores - interlocuções", Silveira (2006) - "Um estudo das capas da revista N ova Escola: 1986-2004”, "Schueler (2005) - "Representações da docência na imprensa pedagógica na Corte imperial (1870-1889): o exemplo da instrução pública”, de Gondra (1997) - “Ecos da república: ciclo de vida e doutrina médica na Revista Pedagógica”, deFischer (2004) - “Imprensa pedagógica como dispositivo desubjetivação da professora moderna: estudo decaso a partir da Revista do Ensino no Brasil/ 1950-1970", de Carval ho (2000) - “Modernidade pedagógica e modelos de formação docente", [...] e, especialmente, os de Frade (2000) - "Imprensa pedagógica: um estudo de três revistas de educação mineiras" e de Frade (1999) "A edição de revistas pedagógicas: alguns elementos para a compreensão do impresso e da imprensa pedagógica". Ressal ta-seque o destaque dado aos trabal hos de Frade (1999 e 2000) é decorrente do fato de a autora ter tido como foco dois periódicos que foram analisados no estudo aqui descrito.

Se a produção científica sobre revistas pedagógicas é diminuta, quando se considera a análise dos escritos sobre educação inclusiva veiculados nesse tipo de publicação constata-se, praticamente, um vácuo. O trabal ho deBarbosa, Mazzonetto eM iranda (2005) éexceção. Os autores efetuaram análises de conteúdo ebi bliométrica dos escritos sobre inclusão escolar publicados na revista N ova Escola entre 1994 e 2004. De modo geral, esse estudo constatou que o periódico por eles estudado contribui deformalimitada para a preparação dos docentes para a educação indusiva, uma vez que as matérias não têm caráter analítico, restringido-se, na maioria das vezes, a relatos superficiais sobre experiências 'bem-sucedidas' de inclusão escolar.

Sem dúvida, a inclusão escolar tem sido um dos debates mais comuns no meio educacional nos últimos anos e é, também, uma das maiores angústias dos 
professores brasileiros. Ainda que se reconheça que a inclusão escolar é responsabilidadedetodos os educadores edas famílias, a Declaração de Salamanca (UNESCO, 1994, s/ p), por exemplo, enfatiza que os "professores, no entanto, possuem um papel fundamental enquanto administradores do processo educacional, apoiando as crianças através do uso de recursos disponíveis, tanto dentro como fora da sala de aula". O documento também ressalta que "[...] programas de treinamento de professores, tanto em serviço como durante a formação, [...]" (s/ p) são fundamentais para o estabelecimento de escolas inclusivas. Há queseacrescentar queesse documento-chaveno âmbito da educação inclusiva propõe que materiais escritos sejam preparados como parte do processo de treinamento de educadores para as mudanças indispensáveis no sistema educacional quando a meta é não deixar ninguém de fora (MANTOAN, 2005).

A literatura científica (ver, por exemplo, MENDES, 2004) e os documentos oficiais (ver, por exemplo, as Diretrizes Curriculares Nacionais para a Formação de Professores da Educação Básica em Nível Superior: Curso de Licenciatura e de Graduação Plena, BRASIL, 2002) estão repletos de alusões ao fato de a capacitação profunda e crítica de candidatos à docência e a formação continuada dos educadores constituírem condição sine qua non para o sucesso da educação inclusiva. Para tanto, várias estratégias devem ser adotadas. Disponibilizar materiais escritos com qualidade elevada em revistas pedagógicasé, indubitavel mente, um meio eficienteeeficaz tanto para a formação acadêmica quanto para a preparação dos educadores em serviço.

As revistas pedagógicas podem ser consideradas meios de comunicação de massa (MCM ). Para Pfromm N etto (1976), os MCM atingem um número grande de pessoas, em curto espaço de tempo, com informações idênticas, o queos tornam poderosos. Citelli (2000) verificou que, dentre as leituras efetuadas semanal mente pelos professores, aparece a revista pedagógica. Os demais escritos lidos pelos docentes pesquisados geralmente não têm caráter educacional.

Frade $(2000, \mathrm{~s} / \mathrm{p})$ ressalta que "desvendar a imprensa pedagógica possibilita, em última instância, conhecer melhor o campo da Educação [...]". Parafraseando a autora, é possível afirmar que desvendar as revistas pedagógicas possibilita, em última instância, conhecer melhor as práticas educacionais queestão sendo adotadas na busca pela escola inclusiva ou, pel o menos, o que se espera dos educadores na educação inclusiva.

\section{0 bjetivos}

Como objetivo geral, propôs-se efetuar análises de conteúdo e bibliométrica de escritos sobre educação inclusiva publicados entre 1994 e 2005 em duas revistas pedagógicas mineiras. Especificamente, propuseram-se: identificar a incidência de escritos sobre educação inclusiva nos periódicos-alvo; caracterizar a tipologia textual (artigos, resenha etc.) desses escritos; descrever os principais temas específicos abordados nos escritos-alvo; analisar os discursos predominantes 
nessas matérias, classificando-os como inclusivistas, integracionistas ou excludentes; fazer uma descrição das necessidades educacionais especiais focadas nos textosalvo; caracterizar o nível e/ ou a modalidade de ensino abordados nos escritosalvo; analisar a abordagem de necessidades educacionais especiais presentes nas publicações analisadas, classificando-as como educacionais, terapêuticas ou educação-terapêutica; efetuar uma caracterização do gênero discursivo (opinativo, reportativo/ descritivo ou analítico) dos escritos; identificar o tipo de autoria e os autores mais frequentes, bem como anal isar a formação ea experiência educacional desses autores; erealizar outras anál ises bibliométricas (como, por exemplo, número de páginas, tipo de artigo, tipo e quantidade de referências bibliográficas).

\section{Método}

\subsection{ATERIAIS}

Serviram como materiais duas revistas pedagógicas de Minas Gerais:

1. A M A E E ducando (ISSN : 0102-0471) - Tem como editor institucional a Fundação A ssociação Mineira de A ção Educacional (A mae). N o total, foram consultadas 94 edições deste periódico, sendo que somente não foi encontrado o número 287 de 1999.

2. Presença Pedagógica (ISSN : 1413-1862) - É editada comercialmente pela Editora Dimensão. Consultaram-se 63 edições desta revista, não sendo encontrados os números um, dois e cinco de 1995.

Tratam-se de periódicos genéricos de divulgação ampla de acordo com a classificação de Ortega, Fávero e Garcia (1998). Caracterizações mais detalhadas dos dois periódicos podem ser encontradas em Frade (1999 e 2000).

A revista AMAE Educando começou a circular sem interrupção em 1967 e tem seu nome decorrente da vinculação com a Associação Mineira de Administração Escolar, no Instituto de Educação de M inas Gerais criada em 1966 e que, em 1998, tornou-se Fundação Amae para Educação e Cultura. (http:/ / www.fundacaoamae.com.br/ )

A revista AMAE Educando divulga experiências e práticas de: Educação Infantil, Ensino Fundamental, cursos de Magistério e Pedagogia. Os trabalhos, direta ou indiretamente relacionados com a educação, podem ser apresentados sob a forma de relatos de experiências, planejamentos, sugestões de atividades e de recursos metodológicos.

Os artigos enviados para publicação em Amae Educando precisam ser, necessariamente, inéditos. Esses textos serão apreciados pela Coordenadoria de Publicações da Fundação A mae e pelo Consel ho Editorial da revista (...) (http:/ / www.fundacaoamae.com.br/ ). 
A revista Presença Pedagógica é mais recente e só começou a circular em janeiro de 1995, ou seja, alguns meses depois da Declaração de Salamanca (UNESCO, 1994). Publicada bimestralmente em Belo Horizonte, pela Editora Dimensão, a revista circula em todo o Brasil eé, segundo a instituição responsável, referência para profissionais da Educação Básica (pedagogos, professores e bibliotecários), professores ealunos das Faculdades de Educação. Em cada edição, o leitor encontra entrevistas com educadores e especialistas, artigos assinados por professores de universidades e da educação básica de diversas regiões brasileiras, reportagens sobre temas em pauta na educação, crítica de produtos culturais destinados ao público infantojuvenil e também para os professores, textos sobre os verbetes (como avaliação, currículo etc.) frequentes nas discussões sobre educação, textos de opinião e reproduções de pinturas, gravuras e esculturas de artistas consagrados para ilustrar os textos publicados. (http:/ / www.presencapedagogica.com.br/ ).

Ressalta-se queforam analisados somenteos exemplares desses periódicos publicados entre 1994 e2005. Quanto ao ano que serviu como ponto partida para o "recorte" temporal efetuado, é necessário destacar que 1994 foi um marco no processo histórico que objetiva o estabelecimento de sistemas educacionais inclusivos, uma vez que foi nessa ocasião que se promulgou a Declaração de Salamanca (UNESCO, 1994). O delimitador final do intervalo temporal (2005) foi adotado considerando uma maior probabilidade de se ter os periódicos nas bibliotecas, já que, talvez, revistas mais recentes não estivessem presentes nos acervos, e o fato daquele documento ter completado mais de uma década no ano em questão. Tratou-se de um período suficiente para que os países signatários do documento começassem a cumprir a meta de não deixar nenhum estudante com necessidadeeducacional especial fora das salas eescolas comuns do sistema regular de ensino, isto é, para que os governos atribuíssem “a mais alta prioridade política e financeira ao aprimoramento de seus sistemas educacionais no sentido de se tornarem aptos a incluírem todas as crianças, independentemente desuas diferenças ou dificuldades individuais" e adotassem "o princípio de educação inclusiva em forma de lei ou de política, matriculando todas as crianças em escolas regulares, a menos que existam fortes razões para agir de outra forma" (UNESCO, 1994, s/ p).

A escolha de duas revistas pedagógicas - A M AE Educando e Presença Pedagógica - foi decorrentetanto da relevância desses periódicos para Minas Gerais, estado onde se localiza a universi dade à qual a presente pesquisa está vinculada, quanto do fato de elas serem publicadas desde, pelo menos, janeiro de 1995. O primeiro motivo indicado, isto é, serem mineiros, confereà pesquisa a possibilidade de ter elevada vali idade ecológica, ainda que limite a validade externa. O segundo fator usado como critério deescolha, ou seja, serem publicadas desdeo ano adotado como marco inicial do intervalo temporal ou, pelo menos, próximo a ele, permitea comparação entre as duas publicações.

Também foi empregada, como material, uma grade de análise desenvolvida pelos autores da pesquisa. Trata-se de um impresso bastantesimples 
que foi reproduzido em fol has de papel eque permitiu o registro das informações bibliográficas e bibliométricas dos textos-alvo, assim como uma tabulação preliminar das outras variáveis pesquisadas (vide Objetivos Específicos).

\subsection{Procedimento}

A coleta de dados foi subdividida em duas etapas: 1ª. Localização das revistas e escritos-alvo; $2^{a}$. A nálises de conteúdo e bibliométrica dos escritos selecionados.

Na primeira etapa, foram consultados acervos debibliotecas del nstituições Educacionais de Minas Gerais e de São Paulo para verificar se neles constavam as revistas-chave. Nessa etapa, os pesquisadores também selecionaram os escritos que abordam o tema-chave educação inclusiva. Foram incluídos todos os textos que tratam da inserção de pessoas com necessidades educacionais especiais em sal as de aula e escolas comuns da rede regular de ensino. Esses materiais também podem aparecer usando expressões como inclusão escolar, educação ediversidade e/ ou integração escolar.

Ressalta-se que restringir a questão da educação inclusiva à escolarização depessoas com necessidades educacionais especiais (ver a definição ea classificação do Ministério da Educação nas Diretrizes Nacionais para Educação Especial na Educação Básica - BRA SI L, 2001) em salas de aula e escolas comuns da rederegular deensino foi uma opção metodológica, já que, atual mente, temas como diversidade étnica e de gênero e outros também têm sido consi derados como parte do debate sobre escolas inclusivas.

Para levar a cabo a segunda etapa, um dos autores efetuou análises de conteúdo e bibliométrica. No caso do primeiro tipo de análise, foi adotada a perspectiva proposta por Bardin (1995). A crescenta-se que, para conferir maior confiabilidade a essa análise, foi efetuada concordância entre juízes, sendo que o outro autor atuou como juiz. Há que se ressaltar que foram obtidos escores de concordância entre anal ista e juiz sempre superiores a 75\%.

Como o índice de concordância entre analista e juiz foi significativo em todos os casos, os dados foram submetidos a uma anál ise quantitativa. Foi adotado um nível de significância de 5\%. Tal decisão foi decorrente das características do objeto de estudo.

\section{Resultados}

Foram encontradas 40 matérias, sendo que 24 (60\%) são da revista AMAE Educando e 16 (40\%) do periódico Presença Pedagógica. Assim, não houve predomínio de publicações de uma ou outra revista $\left(\chi^{2}=1,60 ; \mathrm{gl}=1 ; p=0,21\right)$. Se for consi derada a quanti dade total de edições analisadas das revistas Presença 
Pedagógica ( $N=63$ ) e AMAE Educando $(N=94)$, verifica-se que a média de artigos por número para ambos os periódicos foi de 0,25 , o que evidencia que ambas tendem a dar a mesma atenção para a questão da educação inclusiva.

A Tabela 1 resume os resultados obtidos na análise das variáveis bibliométricas focadas no presente estudo. Dentre elas, considerou-se o ano em que os textos foram publicados. No que se refere a esse aspecto, constatou-se que não há correlação entre os anos de publicação dos dois periódicos $\left(r_{\text {so }}=-0,48\right.$; $p=0,13 ; N=11)$. Verificou-se que os escritos sobre inclusão escolar começaram a ser publicados na Presença Pedagógica a partir de 1997 enquanto a AMAE Educando já tinha publicações no primeiro ano analisado (1994). É preciso destacar que há lacunas temporais nos dois periódicos, sendo que, no total, somente em 1998 não houve publicação com o tema-alvo.

Tabela 1 - Caracterização bi bl iométrica dos escritos sobreinclusão escolar de revistas pedagógicas mineiras.

\begin{tabular}{|c|c|c|c|c|c|c|}
\hline \multirow{2}{*}{$\begin{array}{l}\text { Variáveis bibliométricas } \\
\text { Ano de Publicação }\end{array}$} & \multicolumn{2}{|c|}{ AMAE Educando } & \multicolumn{2}{|c|}{ Presença Pedagógica } & \multicolumn{2}{|c|}{ Total } \\
\hline & $\mathrm{n}$ & $\%$ & $\mathrm{n}$ & $\%$ & $\mathrm{n}$ & $\%$ \\
\hline 2005 & 3 & 12,50 & 2 & 12,50 & 5 & 12,50 \\
\hline 2004 & 2 & 8,33 & 1 & 6,25 & 3 & 7,50 \\
\hline 2003 & 2 & 8,33 & 3 & 18,75 & 5 & 12,50 \\
\hline 2002 & 3 & 12,50 & 2 & 12,50 & 5 & 12,50 \\
\hline 2001 & 1 & 4,17 & 1 & 6,25 & 2 & 5,00 \\
\hline 2000 & 2 & 8,33 & - & - & 2 & 5,00 \\
\hline 1999 & - & - & 5 & 31,25 & 5 & 12,50 \\
\hline 1998 & - & - & - & - & - & - \\
\hline 1997 & - & - & 2 & 12,50 & 2 & 5,00 \\
\hline 1996 & 2 & 8,33 & - & - & 2 & 5,00 \\
\hline 1995 & 4 & 16,67 & - & - & 4 & 10,00 \\
\hline 1994 & 5 & 20,83 & - & - & 5 & 12,50 \\
\hline Total & 24 & 100 & 16 & 100 & 40 & 100 \\
\hline Tipo de matérias & $\mathrm{n}$ & $\%$ & $\mathrm{n}$ & $\%$ & $\mathrm{n}$ & $\%$ \\
\hline Artigo & 19 & 79,17 & 10 & 62,50 & 29 & 72,50 \\
\hline Reportagem & 2 & 8,33 & 3 & 18,75 & 5 & 12,50 \\
\hline Informativo & 3 & 12,50 & 1 & 6,25 & 4 & 10,00 \\
\hline Entrevista & - & - & 2 & 12,50 & 2 & 5,00 \\
\hline Total & 24 & 100 & 16 & 100 & 40 & 100 \\
\hline Gêneros discursivos & $\mathrm{n}$ & $\%$ & $\mathrm{n}$ & $\%$ & $\mathrm{n}$ & $\%$ \\
\hline Descritivo/reportativo & 16 & 66,67 & 4 & 25,00 & 20 & 50,00 \\
\hline Analítico & 8 & 33,33 & 8 & 50,00 & 16 & 40,00 \\
\hline Opinativo & - & - & 4 & 25,00 & 4 & 10,00 \\
\hline Total & 24 & 100 & 16 & 100 & 40 & 100 \\
\hline \multirow{2}{*}{ Quantidade de autores } & $\bar{X}$ & \pm & $\bar{X}$ & \pm & $\bar{X}$ & \pm \\
\hline & 1,13 & 0,85 & 1,13 & 0,50 & 1,13 & 0,72 \\
\hline Caracterização dos autores & $\mathrm{f}$ & $\%$ & $\mathrm{f}$ & $\%$ & $\mathrm{f}$ & $\%$ \\
\hline Professor & 8 & 26,67 & 8 & 50,00 & 16 & 34,78 \\
\hline Pedagogia & 11 & 36,69 & 4 & 25,00 & 15 & 32,61 \\
\hline Psicologia & 5 & 16,67 & 1 & 6,25 & 6 & 13,04 \\
\hline Psicopedagogia & 4 & 13,33 & - & - & 4 & 8,70 \\
\hline Jornalismo & - & - & 2 & 12,50 & 2 & 4,35 \\
\hline Escritor & 2 & 6,67 & 0 & - & 2 & 4,35 \\
\hline Sociologia & - & - & 1 & 6,25 & 1 & 2,17 \\
\hline Total & 30 & 100 & 16 & 100 & 46 & 100 \\
\hline \multirow{2}{*}{ Número de páginas } & $\overline{\mathrm{X}}$ & \pm & $\overline{\mathrm{X}}$ & \pm & $\overline{\mathrm{X}}$ & \pm \\
\hline & 2,46 & 1,67 & 6,69 & 2,87 & 4,15 & 3,03 \\
\hline \multirow{2}{*}{ Referências/Bibliografias } & $\overline{\mathrm{X}}$ & \pm & $\overline{\mathrm{X}}$ & \pm & $\overline{\mathrm{X}}$ & \pm \\
\hline & 2,22 & 3,10 & 10,80 & 4,34 & 5,29 & 5,46 \\
\hline
\end{tabular}


No que se refere ao tipo de matérias publicadas, no geral, predominaram os $\operatorname{artigos}\left(72,50 \% ; n=29 ; \chi^{2}=48,60 ; g l=3 ; p=0,00\right)$. Ao agrupar os resultados e considerar apenas os artigos e as outras matérias, verificou-se que as duas revistas pedagógicas tendem a publicar os primeiros com maior frequência $\left(\chi^{2}=1,34 ; \mathrm{gl}=1\right.$; $p=0,25)$.

No geral ( $n=20 ; 50 \% ; \chi^{2}=10,40 ; g l=2 ; p=0,01$ ) prevaleceram textos cujo gênero discursivo foi classificado como descritivo/ reportativo. Quando se considera os periódicos especificamente, porém, este predomínio não ocorreu tanto no caso da Presença Pedagógica $\left(\chi^{2}=2,00 ; \mathrm{gl}=2 ; \mathrm{p}=0,37\right)$ quanto no caso da AMAE Educando $\left(\chi^{2}=2,67 ; \mathrm{gl}=1 ; p=0,10\right)$.

Já no que diz respeito à quantidade de autores, constatou-se que o periódico AMAE Educando (Média $=1,13 \pm 0,85$ ) e a revista Presença Pedagógica (Média $=1,13 \pm 0,50$ ) não apresentaram diferença significante quando se considera a média deautores por matéria $(U=174,00 ; p=0,51)$. Destaca-seque em ambas as publicações a moda foi de um autor por matéria e que textos com autoria institucional foram computados como zero. Foram encontrados 34 autores, sendo quesomentequatro deles (11,76\%) publicaram mais de uma matéria sobre educação inclusiva no período e periódicos analisados: Elizabet Dias de Sá; José Luiz de Carvalho; Marília da Piedade Marinho Silva; e Rejane de Souza Fontes.

A penas quatro (10\%) textos dos 40 analisados não apresentaram autoria, sendo, dessa forma, provavel mente de responsabilidade da equipe editorial das revistas. Assim, 21 (87,50\%) textos da AMAE Educando e 15 (93,75\%) da Presença Pedagógi ca tinham autoria explicitada, sendo que 19 (79,17\%) da primeira revista e 12 (75\%) da segunda tinham autores caracterizados quanto à formação e/ ou vida profissional. Verificou-se que as caracterizações mais comuns são 'professor' ( $n=16 ; 34,78 \%$ ) e 'pedagogo' ( $n=15 ; 32,61 \%$ ), ou seja, profissionais diretamente envolvidos com a educação escolar.

A o analisar a média do número de páginas dos dois periódicos- Presença

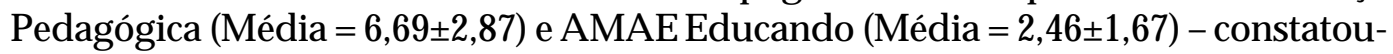
se que o primeiro apresentou uma média maior de páginas $(U=36,00 ; p=0,00)$. No geral, a média de página dos textos foi de $4,15 \pm 3,03$, sendo que o maior deles tem 12 páginas.

Quanto à presença de referências bibliográficas ou bibliografia nos textos, verificaram-se diferenças significantes entre as duas revistas $(U=17,00 ; p=0,00)$, sendo que, na AMAE Educando, há uma proporção equivalente de escritos com e sem referências/ bibliografia e, na Presença Pedagógica, somente uma publicação não possui esse item analisado.

A o analisar as variáveis focadas na análise de conteúdo por revista (Tabela 2), destaca-se, no caso dos temas abordados nos periódicos, a categoria inclusão escolar ( $n=16 ; 40 \%$ ). No periódico AMAE Educando, além do tema supracitado, 
merece menção a quantidade de textos sobre estratégias de ensino para inclusão escolar. A pesar de o tema inclusão escolar em geral ter escores com porcentagem expressiva em ambos os periódicos, constatou-se que as revistas tendem a abordar temas distintos $\left(r_{s o}=0,48 ; p=0,19 ; N=9\right)$.

Tabela 2 - Análise do conteúdo dos escritos sobre inclusão escolar de revistas pedagógicas mineiras.

\begin{tabular}{|c|c|c|c|c|c|c|}
\hline \multirow{2}{*}{$\begin{array}{c}\text { Análise de conteúdo } \\
\text { Temas }\end{array}$} & \multicolumn{2}{|c|}{ AMAE Educando } & \multicolumn{2}{|c|}{$\begin{array}{c}\text { Presença } \\
\text { Pedagógica }\end{array}$} & \multicolumn{2}{|c|}{ Total } \\
\hline & $\mathrm{n}$ & $\%$ & $\mathrm{n}$ & $\%$ & $\mathrm{n}$ & $\%$ \\
\hline Inclusão escolar (geral) & 8 & 33,33 & 8 & 50,00 & 16 & 40,00 \\
\hline Estratégias de ensino & 6 & 25,00 & 3 & 18,75 & 9 & 22,50 \\
\hline Preparação do educador & 3 & 12,50 & 1 & 6,25 & 4 & 10,00 \\
\hline Integração escolar & 2 & 8,33 & 1 & 6,25 & 3 & 7,50 \\
\hline Atividade física e deficiência & 1 & 4,17 & 1 & 6,25 & 2 & 5,00 \\
\hline Exclusão & 2 & 8,33 & - & - & 2 & 5,00 \\
\hline Preconceito & - & - & 2 & 12,50 & 2 & 5,00 \\
\hline Classe especial & 1 & 4,17 & - & - & 1 & 2,50 \\
\hline Características das NEE & 1 & 4,17 & - & - & 1 & 2,50 \\
\hline Discurso & $\mathrm{n}$ & $\%$ & $\mathrm{n}$ & $\%$ & $\mathrm{n}$ & $\%$ \\
\hline Inclusivista & 18 & 75,00 & 15 & 93,75 & 33 & 82,50 \\
\hline Integracionista & 5 & 20,83 & - & - & 5 & 12,50 \\
\hline Excludente & - & - & 1 & 6,25 & 1 & 2,50 \\
\hline Não identificado & 1 & 4,17 & - & - & 1 & 2,50 \\
\hline NEE & $\mathrm{n}$ & $\%$ & $\mathrm{n}$ & $\%$ & $\mathrm{n}$ & $\%$ \\
\hline Geral ou mais de uma NEE & 16 & 66,67 & 14 & 87,50 & 30 & 75,00 \\
\hline Síndrome de Down & 3 & 12,50 & 0 &, 00 & 3 & 7,50 \\
\hline Deficiência Auditiva e Surdez & 2 & 8,33 & 1 & 6,25 & 3 & 7,50 \\
\hline Cegueira e Baixa Visão & 1 & 4,17 & 1 & 6,25 & 2 & 5,00 \\
\hline Altas Habilidades/Superdotação & 1 & 4,17 & - & - & 1 & 2,50 \\
\hline Deficiência Física & 1 & 4,17 & - & - & 1 & 2,50 \\
\hline Abordagem das NEE & $\mathrm{n}$ & $\%$ & $\mathrm{n}$ & $\%$ & $\mathrm{n}$ & $\%$ \\
\hline Abordagem educacional & 22 & 91,67 & 14 & 87,50 & 36 & 90,00 \\
\hline Abordagem educacional e terapêutica & 2 & 8,33 & 2 & 12,50 & 4 & 10,00 \\
\hline Tipo de ensino & $\mathrm{n}$ & $\%$ & $\mathrm{n}$ & $\%$ & $\mathrm{n}$ & $\%$ \\
\hline Ensino em geral & 11 & 45,83 & 13 & 81,25 & 24 & 60,00 \\
\hline Público & 12 & 50,00 & 2 & 12,50 & 14 & 35,00 \\
\hline Privado & 1 & 4,17 & 1 & 6,25 & 2 & 5,00 \\
\hline Nível/Modalidade de ensino & $\mathrm{n}$ & $\%$ & $\mathrm{n}$ & $\%$ & $\mathrm{n}$ & $\%$ \\
\hline Ensino em geral & 17 & 70,83 & 15 & 93,75 & 32 & 80,00 \\
\hline Ensino fundamental & 2 & 8,33 & - & - & 2 & 5,00 \\
\hline Ensino fundamental II & 2 & 8,33 & - & - & 2 & 5,00 \\
\hline Ensino médio & 1 & 4,17 & - & - & 1 & 2,50 \\
\hline Educação especial & - & - & 1 & 6,25 & 1 & 2,50 \\
\hline Ensino fundamental I & 1 & 4,17 & - & - & 1 & 2,50 \\
\hline Educação infantil & 1 & 4,17 & - & - & 1 & 2,50 \\
\hline Total & 24 & 100 & 16 & 100 & 40 & 100 \\
\hline
\end{tabular}

A classificação dos discursos predominantes nos periódicos revelou a dominância do discurso inclusivista $\left(n=33 ; 82,5 \% ; \chi^{2}=71,60 ; g l=3 ; p=0,00\right)$, 
tanto no que se refere à revista AMAE Educando ( $n=18 ; 75 \%)$ quanto ao periódico Presença Pedagógica ( $n=15 ; 93,8 \%$ ).

Ao considerar qual o tipo de Necessidade Educacional Especial (NEE) mais focado nas 24 edições da revista AMAE Educando que foram analisadas, verificou-se que $16(66,67 \%)$ publicações abordavam-nas de forma geral ou faziam menção a mais de uma delas. Algo semel hante ocorreu com o periódico Presença Pedagógica queapresentou 14 (87,50\%) escritos com tal foco. Assim, evidentemente, no geral ( $n=30 ; 75 \%$ ) prevaleceu esse tipo de texto $\left(\chi^{2}=98,60 ; g l=5 ; p=0,00\right.$ ). Ao agrupar os resultados e considerar apenas o tipo de NEE Geral ou mais de uma e as NEE específicas, não houve diferença entre elas $\left(\chi^{2}=2,22 ; \mathrm{gl}=1\right.$; $p=0,14$ ), confirmando que ambas publicaram os primeiros com maior frequência.

Já no que se refere à caracterização das abordagens, de forma geral, prevaleceram textos com abordagem educacional tanto no geral ( $\mathrm{n}=36 ; 90 \%$; $\chi^{2}=25,60 ; \mathrm{gl}=1 ; \mathrm{p}=0,00$ ) quanto nos casos dos periódicos AMAE Educando ( $\mathrm{n}$ $=22 ; 91,7 \% ; \chi^{2}=16,67 ; \mathrm{gl}=1 ; \mathrm{p}=0,00$ ) e Presença Pedagógica ( $\mathrm{n}=14$; $87,5 \% ; \chi^{2}=9,00 ; \mathrm{gl}=1 ; \mathrm{p}=0,00$ ).

Ao analisar o tipo de ensino (público ou privado), no geral, sobressaiu a não especificação desse aspecto ( $n=24 ; 60 \% ; \chi^{2}=18,20 ; \mathrm{gl}=2 ; \mathrm{p}=0,00$ ). O mesmo ocorreu no periódico Presença Pedagógica ( $\mathrm{n}=13 ; 81,25 \% ; \chi^{2}=16,63 ; \mathrm{gl}=2$; $\mathrm{p}=0,00)$. No caso da revista AMAE Educando, prevaleceram $\left(\chi^{2}=9,25 ; \mathrm{gl}=2\right.$; $p=0,01)$ os textos que tratam do ensino público $(n=12 ; 50 \%)$ e os que abordam o ensino em geral ( $n=11 ; 45,83 \%$ ).

No caso do nível/ tipo de ensino, houve predominância do nível geral ou não especificado ( $n=32 ; 80 \% ; \chi^{2}=141,30 ; g l=6 ; p=0,00$ ), constando, pelo menos, um escrito, no total, para cada nível de ensino analisado.

\section{Dıscussão}

N ão obstante a relevância das revistas pedagógicas em geral para a formação dos educadores e, mais especificamente, dos dois periódicos analisados para Minas Gerais, estado que possui uma das maiores redes de ensino do Brasil, os resultados obtidos revelaram insuficiências qualitativas equantitativas nos textos sobre inclusão escolar publicados nesses suportes ao longo de mais de uma década pós-Salamanca. Destaca-se, no entanto, que as limitações não dizem respeito exclusivamente aos dois títulos-alvo do presente estudo; elas - especialmente a superficialidade - estendem-se para a maioria das revistas pedagógicas. Barbosa, Mazzonetto e M iranda (2007), por exemplo, verificaram quea revista N ova Escola - a mais lida pelos docentes (GENTIL, 2006) - possui ainda mais limitações quando se trata de escritos sobre inclusão escolar. 
Assim, há que se reiterar, com preocupação e pesar, que as revistas pedagógicas desempenham um papel fundamental na formação inicial e continuada de educadores, já que, de acordo com Gentil (2006) e Chopin (2004), elas constituem um poderoso veículo de concepções/ representações, valores, e outros, relacionados ao ato educacional. Influenciam, dessa forma, as práticas de ensino, o cotidiano da sala de aula. Costa et al (2007), por exemplo, verificaram que esses periódicos constituem uma das principais leituras efetuadas por professores ao prepararem aulas.

Quanto às características bibliométricas dos escritos sobre inclusão escolar das revistas pedagógicas mineiras, os resultados evidenciaram que eles:

- Já eram publicados na primeira metade da década de 1990 e que há, ainda que breve, uma lacuna temporal na publicação desses textos;

- Têm predominantementea forma deartigo com gênero descritivo/ reportativo, mas também é notada a presença do gênero analítico;

- São decorrentes de uma produção intel ectual de autores isolados, geralmente educadores apresentados como professores e/ ou pedagogos, e não de grupos de pesquisa;

- Têm um número reduzido de páginas, o que limita substancialmente a possibilidade de aprofundar o tema abordado;

- Tendema apresentar referências bibliográficas ou bibliografia parafundamentar o discurso, ainda que em número bastante reduzido.

A síntese das características bibliométricas efetuada no parágrafo anterior revela que as duas revistas analisadas têm, em maior - AMAE Educando - ou menor - Presença Pedagógica - quantidade, atributos de periódicos com perfil essencialmente comercial. Reitera-se que alguns periódicos pedagógicos têm vinculação com MCM etêm metas mercadológicas (ORTEGA; FÁ VERO; GA RCIA, 1998), fazendo com que os objetivos de formação dos professores-leitores coexistam ou sejam secundários aos interesses comerciais.

Há que se destacar, no entanto, que elas também possuem qualidades próprias das publicações científicas, ainda que de forma menos acentuada. Para ilustrar essa afirmação, menciona-se a presença de bibliografias ou referências bibliográficas, e, mesmo no que diz respeito a esse aspecto, foram observadas limitações tanto quantitativas quanto qualitativas. tendem a:

Com relação ao conteúdo das matérias, as revistas pedagógicas mineiras

- Adotar como tema a inclusão escolar de forma global com um discurso, evidentemente, inclusivista;

- Não especificar uma NEE, abordando-as enquanto constructo geral;

- Não especificar o tipo (público ou privado) eo nível (fundamental, médio etc.) de ensino; e 
- Priorizar uma abordagem educacional das NEEs em detrimento de uma abordagem terapêutica.

Com baseem Chopin (2004) eFrade (2000), épossível afirmar queo perfil delineado no parágrafo anterior é um testemunho do que se pensa e do que se faz no âmbito da inclusão escolar em Minas Gerais e, por que não, no Brasil. Há evidências de que a inserção de estudantes com NEEs em salas de aula regulares de escol as comuns tem sido apresentada aos docentes e candidatos à docência de forma ampla, enfatizando os fundamentos legais, pedagógicos gerais efil osóficos da inclusão. Não se consideram a especificidade de cada necessidade e nem os desafios próprios das práticas de ensino específicas necessárias à inclusão de cada uma delas em cada etapa de ensino.

Exige-se que os professores 'incluam', mas não são fornecidas diretrizese orientações sobre como fazê-lo. Há que se destacar que, (...) “embora os princípios básicos que sustentam a educação especial hoje em dia sejam por definição muito simples, levá-los à prática não é nada fácil" (TORRES-GONZÁLES, 2002, p. 92). 'Boas intenções', ainda que sejam fundamentais, e belos discursos não são suficientes para transformar o ensino homogêneo ehomogeneizantequecaracteriza a maioria das escolas brasileiras.

Não se trata de cobrar às revistas pedagógicas que apresentem um ‘manual da inclusão escolar' para os leitores, mas, sim, que anal isem a educação de diferentes tipos de NEEs de forma profunda, crítica, contextualizada e, principalmente, propositiva. Para queisso ocorra, no entanto, são necessários conhecimentoscientíficos, especialmente pesquisas com intervenção e pesquisação que devem ser divulgadas para servirem com base para a formação inicial e continuada dos educadores.

A faceta positiva mais positiva do conteúdo das matérias sobre inclusão escolar publicadas em revistas pedagógicas mineiras abrange o discurso inclusivista, que, todavia, carece de crítica etem caráter panfletário, ea abordagem educacional das NEEs, ainda que muito genérica. N esse último caso, da mesma forma que Torres-Gonzáles (2002) observou no contexto espanhol, constata-se, na realidade, a coexistência da perspectiva educacional eda terapêutica. Assim, ainda que prevaleça o que esse autor descreveu como "currículo como resposta educacional à diversidade" (p. 91), também há, em menor escala, ênfase em características do aluno, "nos déficits por ele apresentados. Esse enfoque parte do diagnóstico dessas deficiências e centra-se na criação de situações educativas diferenciais-especiais para atendê-las" (p. 95).

Do ponto devista bibliométrico, apesar deos periódicos-alvo terem publicado proporcionalmente a mesma quantidade de textos, geralmente artigos escritos por um único autor, verifica-se que a Presença Pedagógica publica textos mais longos, com bibliografias ou referências bibliográficas e em momentos (anos) distintos. No queconcerneao conteúdo, as diferenças entreas revistas ocorrem nostemas abordados e no fato dea AMAE Educando ter mais textos voltados para o ensino público. 


\section{CONSIDERAÇÕES FINAIS}

A pesar das limitações da presente investigação (número restrito de periódicos analisados e a não localização de todos os números publicados), os resultados obtidos ea análise efetuada evidenciam quea revista AMAE Educando tem um caráter jornalístico mais saliente e que o periódico Presença Pedagógica aproxima-se mais dos periódicos educacionais classificados como científicos por reservar mais espaço para textos analíticos e fundamentados, ainda que minimamente, na literatura existente. A maneira como os escritos publicados nos periódicos abordam a educação inclusiva permite afirmar, no entanto, que ambas não se mostram capazes de, isoladamente ou em conjunto, constituir uma ferramenta que colabora efetivamente para a formação básica e continuada de professores que atuam em escolas inclusivas. A mbas precisam progredir tanto do ponto de vista pedagógico quanto do científico para cumprirem o papel de serem suportes efetivos para a preparação de educadores para o desenvolvimento da educação inclusiva.

"Se tomarmos em perspectiva a relação dos professores com as revistas (pedagógicas), podemos afirmar que elas são lidas, buscadas, pel os professores e têm seus conteúdos, muitas vezes, utilizados" (GENTIL, 2006, p. 132). Assim, não se trata de sugerir aos docentes que não leiam tais publicações, uma vez que elas constituem o principal componente do pequeno repertório de leituras de parcela significativa dos educadores. Urge qualificá-las, torná-las ferramentas que podem propiciar contribuições efetivas para a formação inicial e continuada desses profissionais.

Os textos anal isados desses periódicos representam, simultaneamente, um produto e são produtores da 'inclusão escolar' que tem sido real izada no Brasil. Trata-se de uma inclusão escolar entendida e praticada de forma superficial. Da forma como tem sido conduzida, restringiu-se a um processo que insere alunos com NEE nas salas de aula comuns da rede regular de ensino sem transformar as práticas pedagógicas adotadas e, por consequência, de um ato não inclusivo. De fato, apenas gera formas mais sutis de exclusão, porém, agora, 'dentro'.

A inclusão escolar tem como condição sine qua non a formação dos educadores, especialmente dos professores. Porém, como o faz Rodrigues (2006, p. 6), é preciso destacar que

[...] um professor não é um técnico (no sentido de aplicar técnicas relativamente normalizadas e previamente conhecidas) nem éum funcionário (isto é, uma pessoa que executa funções enquadrado por uma cadeia hierárquica perfeitamente definida). A profissão de professor exige uma grande versatilidade dado que se Ihe pede queaja com uma grande autonomia eseja capaz dedelinear edesenvolver planos de intervenção em condições muito diferentes. Para desenvolver esta competência tão criativa e complexa, não basta uma formação acadêmica; é necessária também uma formação profissional [...]. 
Assim, se as revistas pedagógicas pretendem formar o formador para escolas inclusivas, éindispensável que elas publiquem textos sobre inclusão escolar queanal isem crítica e criativamente a diversi dadeem sal a de aula, que promovam a autonomia docente perante as NEE e outras diferenças individuais esociais, que promovam a arte e a ciência de criar estratégias pedagógicas capazes de acolher, manter e desenvolver todos os al unos e que, efetivamente, sejam ferramentas que complementem a formação profissional dos atuais e futuros educadores.

\section{Referências}

BARBOSA, A. J. G.; MAZZONETTO, K.; MIRANDA, J. A. Inclusão escolar na revista Nova Escola. In: CON GRESSO BRASI LEIRO MULTIDISCIPLINAR DE EDUCAÇÃO ESPECIAL, 4., Londrina. A nais... Londrina: A BPEE. 2007, CD-ROM.

BARDIN, L. A nálise de conteúdo. Lisboa: Edições 70, 1995.

BARROS, T. N.; GOMES, E. O perfil dos professores leitores das séries iniciais e a prática de leitura em sal a de aula. Revista CEFA C, v.10, n.3, p.332-342, 2008.

BARRETO, D. A. B. Leitura sobre leituras. Tecitura, v. 1, n. 2, 2006. Disponível em http:/ / tecitura.juvencioterra.edu.br, acesso em 10 jun. 2008.

BRASI L. D iretrizes Curriculares N acionais para a Formação de Professores da E ducação Básica em N ível Superior: Curso de Licenciatura e de Graduação Plena. Brasília/ DF: A utor, 2002. Disponível em http:/ / portal .mec.gov.br/ seesp/ , acesso em 06 maio 2005.

BRASIL. D iretrizes N acionais para E ducação Especial na Educação Básica. Brasília/ DF. 2001. Disponível em http:/ / portal.mec.gov.br/ seesp/ , acesso em 06 de maio de 2005.

CARVALHO, M. M. C. Modernidade pedagógica e modelos de formação docente. São Paulo em Perspectiva, v.14, n.1, p.111-120, 2000.

CHOPIN , A. História dos livros e das edições di dáticas: sobre o estado da arte. Educação e Pesquisa, v. 30, n. 3, p. 549-566, 2004.

CITELLI, A. Comunicação e edu cação: a linguagem em movimento. São Paulo: Cortez, 2000. COSTA, W. A . et al. Recursos informacionais: importante al iado no processo de elaboração dos planos de aulas. Ciência da Informação, n. 23, p. 92-112, 2007.

FISCHER, B. D. Imprensa pedagógica como dispositivo desubjetivação da professora moderna: estudo de caso a partir da Revista do Ensino no Brasil/ 1950-1970. Linhas, v.5, n.1, p.11-25, 2004.

FRADE, I. C. A. S. Imprensa pedagógica: um estudo de três revistas mineiras destinadas a professores. 2000. Tese (Doutorado) - Faculdade de Educação, Universidade Federal de Minas Gerais, Belo Horizonte.

FRADE, I. C. A . S. A edição de revistas pedagógicas: al guns elementos para a compreensão do impresso eda imprensa pedagógica. In: CON GRESSO BRA SI LEIRO DE CIÊN CIASDA COMUNICAÇÃO, 23., Rio de Janeiro: INTERCOM - Sociedade Brasileira de Estudos Interdisciplinares da Comunicação, 1999. Anais.... Disponível em http:// www.intercom.org.br/ papers/ xxii-ci/ gt04/ art-gt04.html, acesso em: 10 mar. 2006.

GENTIL, M. S. R evistas da área da E ducação e professores - interlocuções. 2006. Tese(Doutorado) - Faculdade de Educação, Universidade Estadual de Campinas, Campinas. 
GONDRA, J. G. Ecos da República: ciclo devida e doutrina médica na Revista Pedagógica. In: REUNIÃO ANUAL DA ANPED, 20., 1997, Caxambu. Caderno de Resumos... Caxambu, 1997. v.1. p.117-118.

MANTOAN, M. T. E. . Não há mal que sempre dure. Ponto de Encontro Revista Pedagógica, v.7, n.7, p.6-6, 2005.

MARINHO, M. PRÓ-LEITURA, perspectivas interdisciplinares: a formação do professor. In: EN CONTRO DE EXTEN SÃ O DA UNIVERSIDADE FEDERAL DE MINASGERAIS, 7., Belo Horizonte: UFMG, 2004. A nais... Disponível em: www.ufmg.br/ proex/ arquivos/ 7Encontro/ Educa161.pdf acesso em 30 mar. 2006.

MENDES, E. G. Construindo um “Iocus" de pesquisa sobre inclusão escolar. In: MENDES, E. G.; ALMEIDA, M. A.; WILLIANS, L. C. A. (Org.). Temas em educação especial: avanços recentes. São Carlos: EdUFSCar, 2004. p.221.-230.

ORTEGA, C.; FÁVERO, O.; GARCIA, W. Análise dos periódicos de educação. Revista Brasileira de Estudos Pedagógicos, v.79, n.193, p.161-191, 1998.

PFROMM NETTO, S. Tecnol ogia da edu cação e comunicação de massa. São Paulo: Pioneira, 1976.

RAMOS, M. E. T. 0 ensino de história na revista N ova Escola (1986-2002): cultura midiática, currículo e ação docente. Tese (Doutorado em Educação) - Programa de Pós-graduação em Educação, Universidade Federal do Paraná, Curitiba 2009.

RODRIGUES, D. Dez idéias (mal) feitas sobre a educação inclusiva. In: RODRIGUES, D. (Org.). Inclusão e educação: doze ol hares sobre a educação inclusiva. São Paulo: Summus, 2006. p. 1-16. Disponível em http:/ / redeinclusao.web.ua.pt acesso em 18 ago. 2008.

SCHUELER, A. F. Representações da docência na imprensa pedagógica na Corte imperial (1870-1889): o exemplo da instrução pública. Educação eP esquisa, v. 31, n. 3, p. 379-390, 2005.

SILVEIRA, F. R. U m estudo das capas da revista N ova Escola: 1986-2004. 2006. Dissertação (Mestrado) - Faculdade de Educação, Universidade Estadual de Campinas, Campinas/ SP.

SMOLKA, A. L. B.; GENTIL, M. S. Duas revistas, três artigos, múltiplas vozes: um estudo sobre modos de dizer e posições sociais em textos para professores. Cadernos CEDES, v.24, n.63, p.193-213, 2004.

TORRES-GONZÁLES, J. A. E ducação e diversidade: bases didáticas e organizativas. Porto Alegre: ARTMED, 2002.

UNESCO. D eclaração de Salamanca: sobre princípios e práticas na área das necessidades educativas especiais. 1994. Disponível em ttp:/ / portal.mec.gov.br/ seesp/ , acesso em 06 maio 2005.

Recebido em: 22/ 06/ 2010

A provado em: 04/ 11/ 2010 